\title{
Radio Environment Analysis at Balai Cerap KUSZA for Solar Burst Study
}

\author{
Marhamah Mohd Shafie ${ }^{\#}$, Roslan Umar ${ }^{\#}$, Nor Hazmin Sabri ${ }^{*}$, Nur Zulaikha Mohd Afandi", Zainol Abidin \\ Ibrahim $^{\$}$ \\ ${ }^{\#}$ East Coast Environmental Research Institute (ESERI), Universiti Sultan Zainal Abidin, 21300 Kuala Nerus, Terengganu, Malaysia \\ E-mail:marhamah92@yahoo.com; roslan@unisza.edu.my; zulaikhafendy@yahoo.com.my \\ ${ }^{*}$ School of Fundamental Science, Universiti Malaysia Terengganu, 21030, Terengganu, Malaysia \\ E-mail: norhazmin@umt.edu.my \\ ${ }^{\$}$ Physics Department, Faculty of Science, University of Malaya, 50603 Kuala Lumpur, Malaysia \\ E-mail:drzai@um.edu.my
}

\begin{abstract}
Solar radio burst study is one of the new researches done in radio astronomy field in Malaysia. Solar radio burst is associated with Coronal Mass Ejections (CMEs). It occurs when magnetic storm collides with Earth's magnetosphere. In this paper, we present the level of radio frequency interference (RFI) at selected sites in Malaysia; ESERI (ECE), Balai Cerap KUSZA (BCK), Sungai Chantek (SGC) and Hentian Serdang (HSRDG) focusing on wideband (30kHz-1000 MHz. The threshold for all selected sites is $-76.3741 \mathrm{dBm}( \pm 7.3887),-74.4022 \mathrm{dBm}( \pm 9.8143),-73.736 \mathrm{dBm}( \pm 9.4494)$ and $-66.4082 \mathrm{dBm}( \pm 13.4290)$ respectively. This study was done to survey the status of frequency allocation in Malaysia for radio astronomy study. In this frequency ranges, radio astronomical sources found are pulsar, deuterium line (DI) and solar radio burst. These radio astronomical sources can be studied best at BCK compared to other sites. This is important to radio astronomer in Malaysia especially in solar burst detection to identify the best site for observation. This study also may provide RFI database to radio astronomers to refer to before conducting an observation.
\end{abstract}

Keywords — radio frequency interference; solar radio burst; e-CALLISTO; spectrum survey

\section{INTRODUCTION}

Recent years have seen the growth in the study of solar radio burst in Malaysia, due to new development of solar radio astronomy in Malaysia which begins in early 2011 [1]. The impact of the solar cycle on Earth and human activity is certainly the most important aspect of radio astronomy towards human kind. Despite its intensive study by numerous countries with their advanced technology, there is still much about solar activity that is not understood. One reason for this long period of study is the fact that solar has its maximum and minimum cycle which is about 11 years period. The best time to study solar activity is during active sun. Nonetheless, during quiet sun, solar activity is still continuously being studied by researchers from countries including Malaysia.

Solar radio burst is classified into 5 types in the 1960s which are Type I, Type II, Type III, stationary Type IV, moving Type IV, flare continua and Type V as shown in Fig. 1 [2]. Solar radio burst was first discovered during World
War II when the noise was noticed to occur during daytime only and damaged the radar systems at that time [3]. A burst of energy from the Sun have the ability to disrupt radar system, Global Positioning Satellite (GPS), cable TV, radio and satellite communications [4]. In many countries, a lot of mission were done such as two-spacecraft mission (STEREO), Hinode probe, Solar and Heliospheric Observatory (SOHO) probe and the Ulysses space probe to study solar activity [5], [6].

Radio astronomers are recommended by ITU (ITU-R RA.769-2) to select a free-interference site for radio observation [7]. More recently, RFI mitigation was done to eliminate RFI sources from radio astronomical data. Several techniques for RFI mitigation, mainly by eliminating the non-Gaussian features in data observed is demonstrated [8]. Another method of RFI mitigation was done by using correlations of spectral intensity fluctuations [9]. Outliers in the data were excluded, and a map of correlations was obtained. 


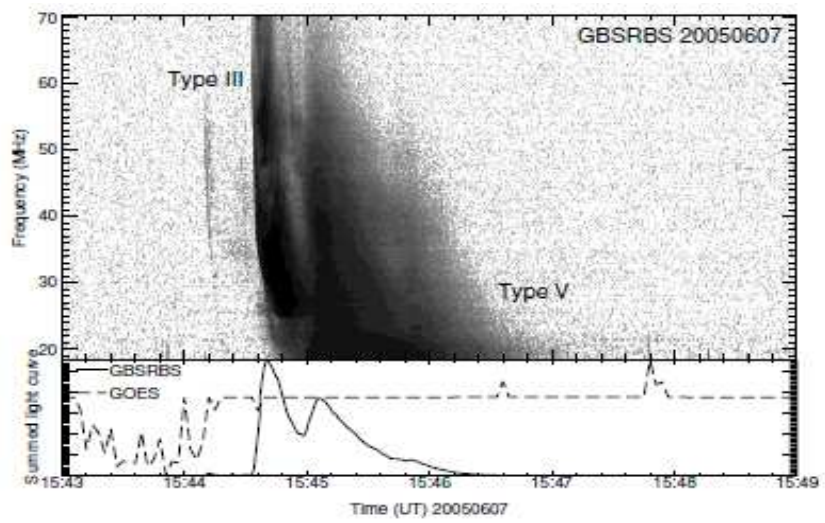

(a)

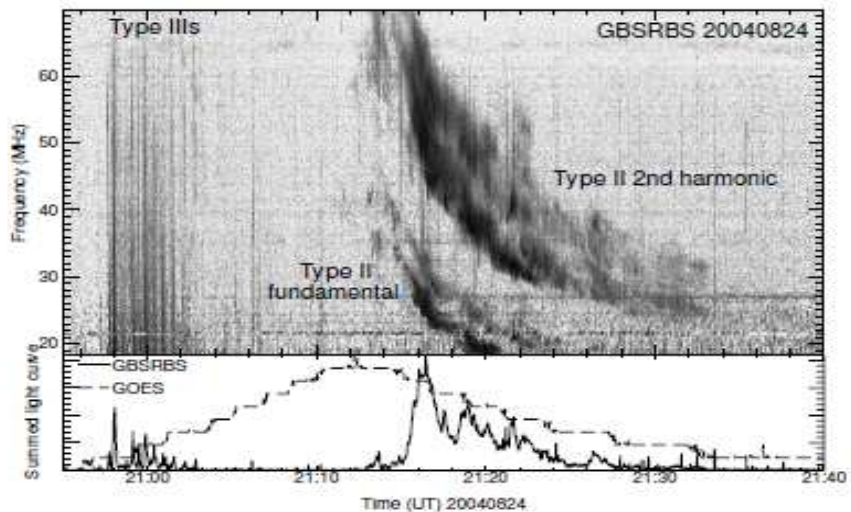

(b)

Fig. 1 Solar burst for (a) Type III and V (b) Type II [10]

Another excision method has been done by researchers is using Artificial Neural Network (ANN) to eliminate RFI from astronomical sources. It detects pulsar candidates automatically using ANN technique. The study successfully classified pulsar candidates into sub-classes to auto-detect the standard pulsars from RFI signal detected in the observation. Meanwhile, a similar study has implemented adaptive RFI filters embedded for pulsar observing system [11]. The observed and predicted signal attenuation of the
RFI is compared using the similar filter. Since the pulsar signal which also known as rotating neutron star exhibit very small signal at a frequency of $50-600 \mathrm{MHz}$ as shown in Fig. 2 , RFI mitigation technique is vital during conducting the observation [12].

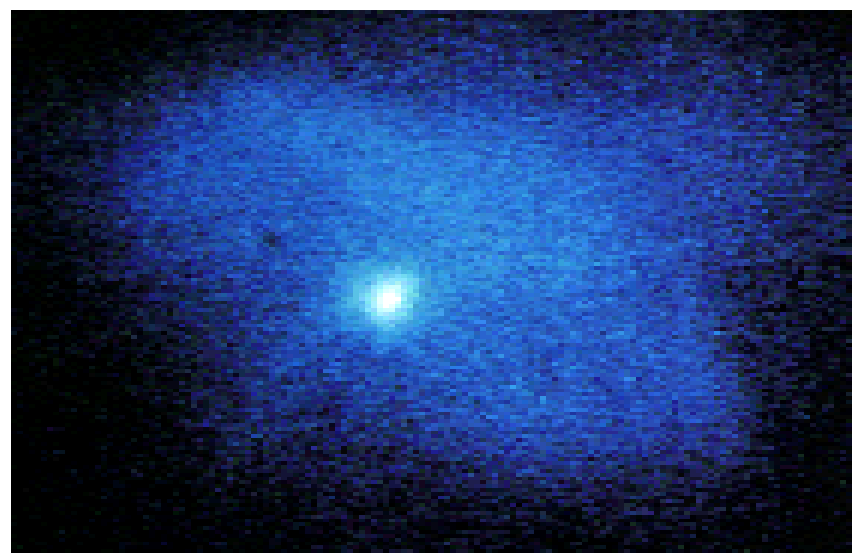

Fig. 2 Crab Nebula surrounding the bright pulsar observed by Einstein XRay Observatory (Credit to NASA)

Spectral lines were also studied by several researchers. They tried to eliminate RFI from their deuterium line (DI) observation data at Haystack Observatory in Westford, Massachutes. Using 12 directional Yagi antenna, the RFI signal were detected, and the sources of RFI was identified. Similar sources of RFI such as telecommunication signal usually are continuous-wave $(\mathrm{CW})$ signal properties and are narrowband. These $\mathrm{CW}$-like sources are excluded in the data analysis, reducing the RFI effect in DI spectrum [13]. Other than that, any signals that exceed eight sigma level are considered as RFI and excised using data processing technique. The mitigation technique was done as shown in Fig. 3. Due to the very small signal from DI which is about $50 \mathrm{~dB}$ weaker than hydrogen line (HI) signal, RFI must be eliminated [26].

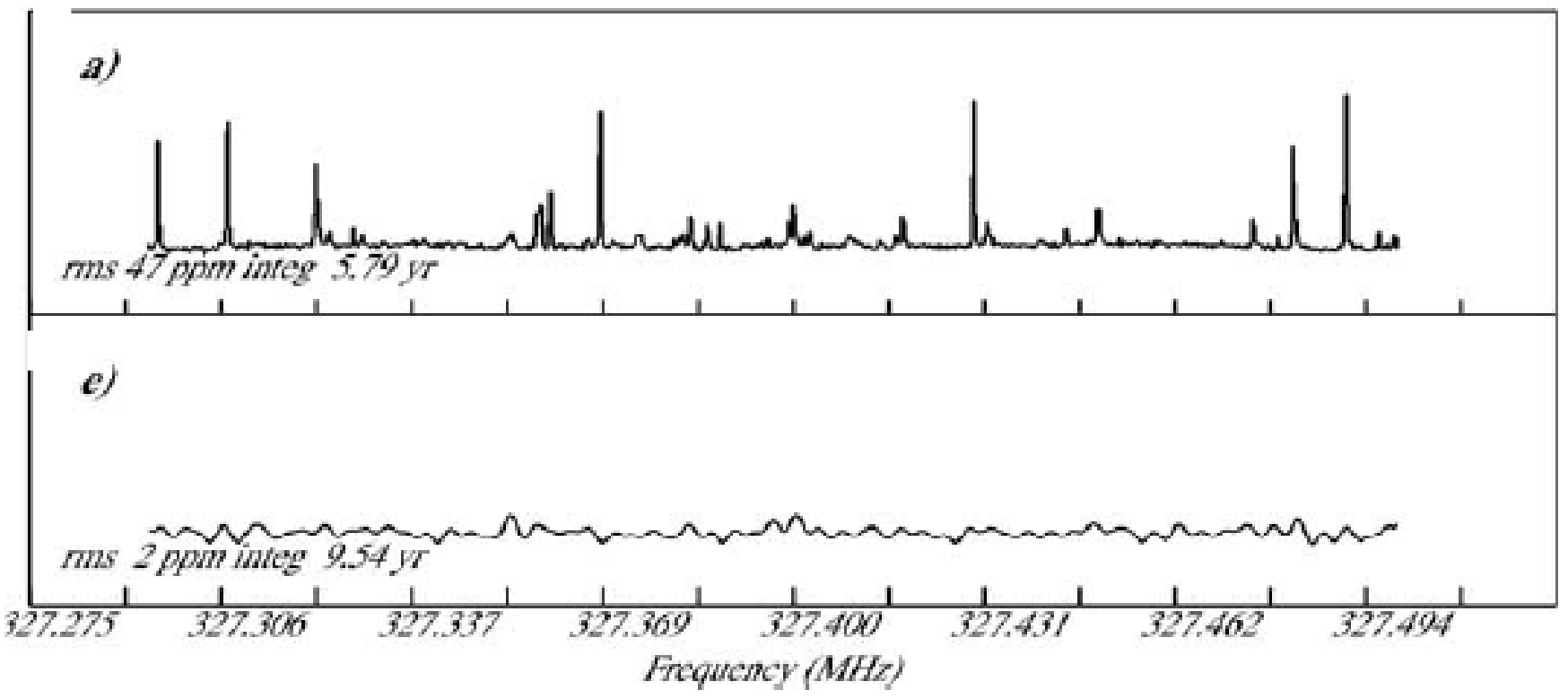

Fig. 3 Sources of RFI are detected in the first picture, while mitigation have been done in the second picture [13] 
While there have been previous studies done on RFI monitoring for solar monitoring purposes in Malaysia, such an approach have not been made in east coast area of Peninsular Malaysia using CALLISTO (Compound LowCost Low-Frequency Transportable Observatories) spectrometer due to the technical limitations [14], [15]. Therefore, a different instrument yet similar analysis method are used to monitor RFI for east coast database and future development of CALLISTO spectrometer in East Coast of Peninsular Malaysia. There is some interference originated from military satellite and local electronics devices due to human generated RFI in the range of 1-900 MHz. However, all reserved frequencies are still available and not interfered by local RFI [14]. It is important to know the population density of the local site as it was one of the main contributors in human generated RFI [16]. Comparison of several sites to determine the site with low RFI for future radio astronomical observation. By focusing on the L-band (1-2 GHz), they divided L-band window into four windows namely as window A, B, C and D for all sites. It is suggested to protect L-band window since the important spectral line; $\mathrm{HI}$ exists in this window with the frequency of $1420 \mathrm{MHz}$. The RFI detected in this study are compared with International Telecommunication Union (ITU) ITU-R RA. 769-2. The recommended RFI by ITU depend on the spectral line itself, differs for each spectral lines. Although previous research has yet implemented the mitigation techniques, the RFI detected at several sites could be the database for reference to other astronomers [17].

In this paper, we will look specifically at the RFI status in broadband (1-1000 MHz) for radio astronomy at East Coast area of Peninsular Malaysia.

Spectrum survey has been done in Malaysia and summarized in Table 1 as conducted by previous researchers at different sites [10], [18]-[23]. According to this database, Merang which is located at East Coast of Peninsular Malaysia has the lowest RFI level compared to other sites. East Coast of Peninsular Malaysia is still in developing stages for its industrial activities. Thus, the level of RFI is considered lowest compared to industrial states mainly located at West Coast of Peninsular Malaysia.

TABLE I

AVERAGE SignAl LEVELS IN MALAYSIA

\begin{tabular}{|l|l|}
\hline Site & RFI Level (dBm) \\
\hline Meteorology Station UM & -83.054 \\
\hline Physics Dpt. & -86.290 \\
\hline National Land and Survey Institute & -94.347 \\
\hline Jelebu & -95.290 \\
\hline Lubuk Cina & -97.777 \\
\hline Langkawi & -97.734 \\
\hline UPSI & -98.3 \\
\hline Kg. Bertam & -98.4828 \\
\hline UM & -98.7 \\
\hline UiTM & -99.900 \\
\hline Faculty of Applied Science (Indoor) & -100.007 \\
\hline Kg. Sekayu & -100.242 \\
\hline Padang Square (Outdoor) & -100.3 \\
\hline Langkawi & -100.330 \\
\hline Merang & -100.375 \\
\hline
\end{tabular}

To observe radio astronomical sources, it is important to choose low RFI sites [16], [24]. The idea to select the best site by using Geographical Information System (GIS) technique is proposed [25]. They consider climate properties, weather conditions, anthropogenic factors and geographical factors as multi-criteria decision analysis (MCDA) technique before integrated with GIS. Suitable locations for radio telescope should be in minimum population density of 0-200 peoples per square kilometres [18]. Similar to the Green Bank Observatory, it is illegal to use transportation in the observatory to preserve the spectrum from RFI signals [19].

This study is done to provide a more detailed spectrum survey database at several sites in Malaysia especially in East Coast of Peninsular Malaysia. The database may help radio astronomers to know the RFI level at certain sites before conducting observations. RFI mitigation could be done using the RFI database recorded at East Coast of Peninsular Malaysia. Moreover, we are hoping that radio astronomical observation can be done by using CALLISTO spectrometer at East Coast of Peninsular Malaysia in the future.

In this paper, we will describe the spectrum survey at selected sites and show examples of RFI sources found and the results of the spectrum overview from 1-1000 MHz. Section 2 describes the method used for spectrum survey, including site selection and data analysis method and. examples of RFI sources found and spectrum overview, as well as the RFI lowest sites. In Section 3, the results are discussed. Finally, in Section 4, conclusions are drawn and discussed.

\section{MATERIAL AND METHOD}

RFI monitoring is one of the first steps in setting up a radio observatory, radio telescope, as well as observing solar radio activity. RFI have to be mitigated before setting up a radio telescope and conducting astronomical observation. One measure of RFI is its baseline, which is often differed by the observation sites and depending on the environment from the surrounding. It is important to perform RFI detection to produce a liable data for solar radio burst.

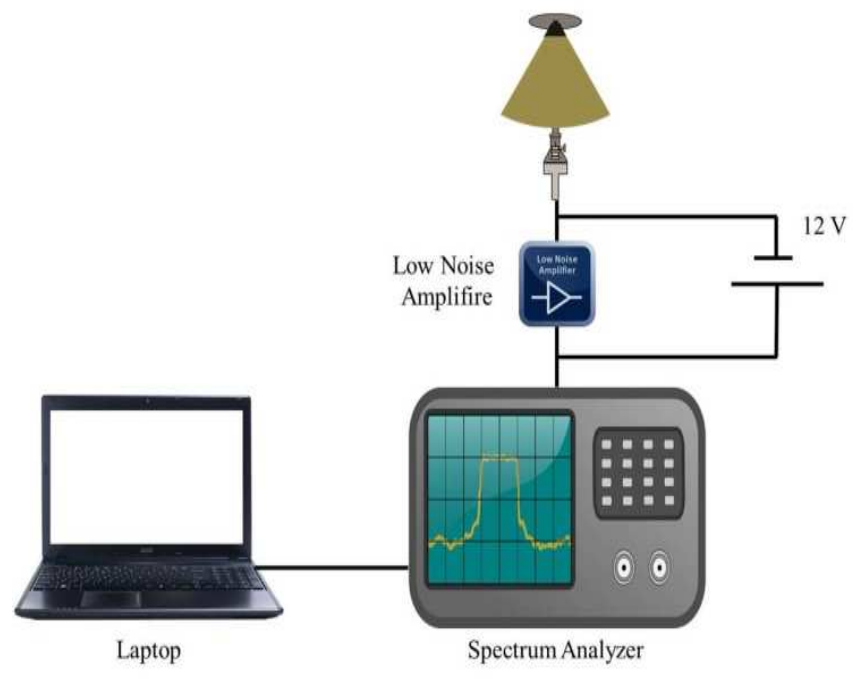

Fig. 4 Instrument setup for RFI monitoring 
We used discone antenna equipped with $1400 \mathrm{MHz}$ Low Noise Amplifier (LNA), which is connected to a spectrum analyser that covers selected frequencies (1-1000 MHz) with a resolution bandwidth of $180 \mathrm{kHz}$ as shown in Fig. 4 . Discone antenna act as a receiver to detect RFI signals from the environment. It is pointing towards the zenith. The Omni-directional antenna is used due to its omnidirectional radiation pattern which covers in all direction. It is important to detect all potential sources of RFI [20].

RFI monitoring was done at a different location which is BCK (Balai Cerap KUSZA), ECE (ESERI), SGC (Sungai Chantek) and HSRDG (Hentian Serdang). BCK are located on a hill nearby east coastal area of Setiu, Terengganu. There is jetty located nearby BCK. ECE was located near the residential area of Kuala Nerus. Meanwhile, for SGC, it is located far from the residential area, but there is base station found near the observation site. HSRDG was located in the residential area near Serdang city. Population density is not considered in this study specifically, but it is used to compare the RFI sources at each observation sites. RFI sources may differ for each site due to the distance of observation sites from the base station and residential area.

The observation was done during a period of time starting from morning until noon. Data were collected for every second for each site to determine the prominent sources for each location and the RFI baseline. The average of the power level for an hour is obtained after calculating the mean power level for each minute. The prominent peaks are identified to determine which spectrum are still free from RFI signals.

\section{RESULTS AND DISCUSSION}

\section{A. RFI Monitoring}

The average of RFI found in ECE, BCK, SGC, and HSRDG is shown in Fig. 5. There are several prominent peaks found which are $225.0 \mathrm{MHz}, 382.5 \mathrm{MHz}, 675 \mathrm{MHz}$, 877.5 MHz and $945 \mathrm{MHz}$. All of these prominent peaks are coming from telecommunication systems which originated from the base station nearby as in Table 2 .

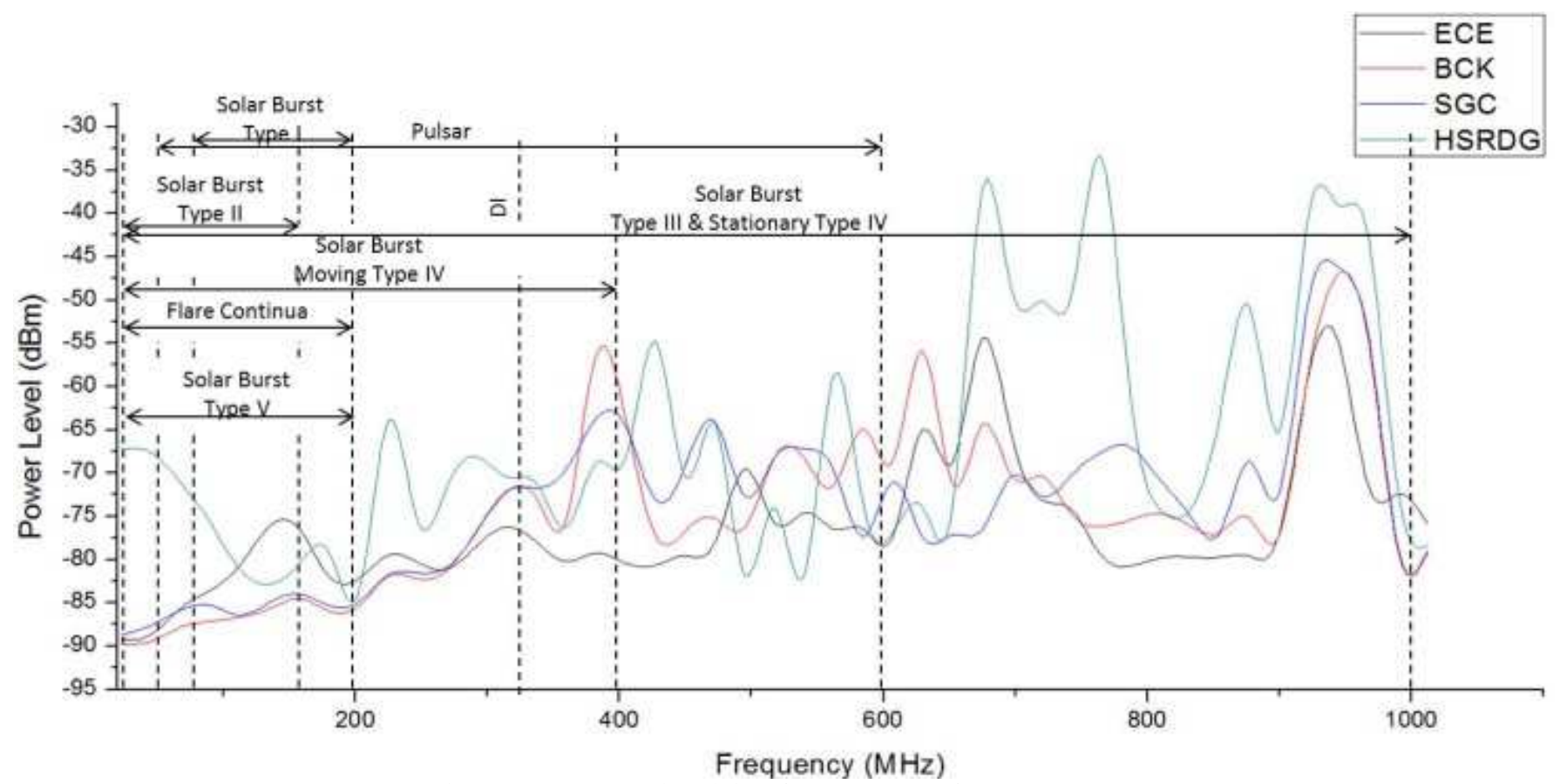

Fig. 5 RFI survey at selected sites, frequency ranges from 1-1000 MHz.

The average of RFI observed at all sites shows slightly similar baseline except at HSRDG with average RFI $66.4082 \mathrm{dBm}( \pm 13.4290)$ which shows a high RFI level. Lower RFI level was seen at ECE, BCK and SGC with power level $-76.3741 \mathrm{dBm}( \pm 7.3887),-74.4022 \mathrm{dBm}$ $( \pm 9.8143)$ and $-73.7360 \mathrm{dBm}( \pm 9.4494)$ respectively.

There were several radio astronomical sources found in the frequency ranges from $1-1000 \mathrm{MHz}$ which mainly are solar radio burst, radio astronomical lines, and pulsar. The average signal strength for radio astronomical objects found in these frequency ranges is summarized in Table 2.

\section{B. Radio Astronomical Sources}

Average of the power level for radio astronomical sources found in frequency range are tabulated in Table 3 and summarized in Fig. 6. It is found that HSRDG has the highest power level for all radio astronomical sources.

TABLE III

RAdio FREQUency SOURCES AT SURVEYed SitEs (MCMC)

\begin{tabular}{|l|l|}
\hline Frequency (MHz) & Source \\
\hline 225.0 & $\begin{array}{l}\text { Analogue TV and digital sound } \\
\text { broadcasting (Channel 12) }\end{array}$ \\
\hline 382.5 & Digital trunked radio (Lower band) \\
\hline 675.0 & $\begin{array}{l}\text { Analogue TV and digital terrestrial } \\
\text { television including terrestrial sound } \\
\text { broadcasting (RTM TV1) }\end{array}$ \\
\hline 877.0 & $\begin{array}{l}\text { Fixed wireless access for code division } \\
\text { multiple access systems in band 800 MHz } \\
\text { (CDMA800)-TM (upper band) }\end{array}$ \\
\hline 945.0 & Mobile phone application \\
\hline
\end{tabular}


This indicates that the frequencies for all radio astronomical sources are most likely to be affected by RFI sources at HSRDG. HSRDG are located close to the main road with heavy traffics. Meanwhile, radio astronomical lines at BCK have low power level compared to other sites.

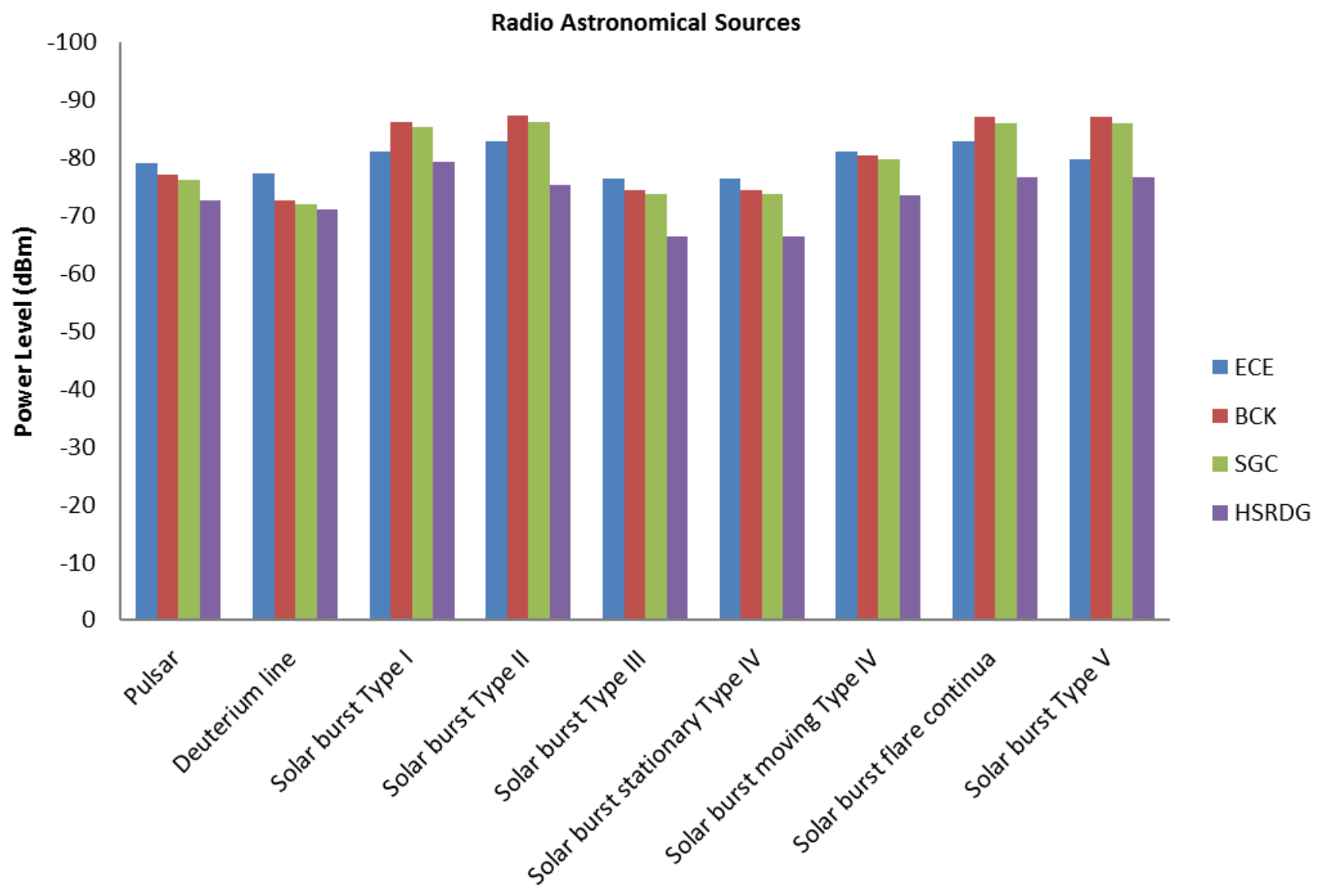

Fig. 6 Average power level $(\mathrm{dBm})$ for radio astronomical sources found in frequency range from 1-1000 MHz at selected sites

It is clear that only solar burst Type I, Type II, flare continua and Type IV have low average power level for all location. Due to the results, BCK are considered to be the best location for radio astronomical observation in ranges of 1-1000 MHz compared to other sites.

TABLE IIIII

AVERAGE FREQUENCY/STANDARD DEVIATION (DBM) AND RADIO ASTRONOMICAL OBSERVATION IN FREQUENCY RANGE FROM 1-1000 MHZ

\begin{tabular}{|l|l|l|l|l|l|l|l|l|}
\hline Sites & \multicolumn{2}{|c|}{ ECE } & \multicolumn{2}{c|}{ BCK } & \multicolumn{3}{c|}{ SGC } & \multicolumn{2}{c|}{ HRSDG } \\
\hline $\begin{array}{l}\text { Pulsar } \\
(50-600 \mathrm{MHz})\end{array}$ & -79.1134 & \pm 3.7566 & -76.9913 & \pm 8.6499 & -76.1181 & \pm 7.9883 & -72.5894 & \pm 7.3547 \\
\hline $\begin{array}{l}\text { Deuterium line } \\
(327.384 \mathrm{MHz})\end{array}$ & -77.1518 & \pm 1.2743 & -72.5741 & \pm 0.5774 & -71.8896 & \pm 0.1966 & -70.9078 & \pm 0.6064 \\
\hline $\begin{array}{l}\text { Solar burst Type I } \\
(80-200 \mathrm{MHz})\end{array}$ & -80.9343 & \pm 3.5216 & -86.1643 & \pm 1.1169 & -85.2524 & \pm 0.7609 & -79.1740 & \pm 4.4206 \\
\hline $\begin{array}{l}\text { Solar burst Type II } \\
(20-150 \mathrm{MHz})\end{array}$ & -82.8985 & \pm 5.3727 & -87.2852 & \pm 1.8995 & -86.1271 & \pm 1.5891 & -75.1658 & \pm 6.5776 \\
\hline $\begin{array}{l}\text { Solar burst Type III } \\
(10 \mathrm{kHz}-1 \mathrm{GHz})\end{array}$ & -76.3741 & \pm 7.3887 & -74.4022 & \pm 9.81427 & -73.7360 & \pm 9.4494 & -66.4082 & \pm 13.4290 \\
\hline $\begin{array}{l}\text { Solar burst stationary Type IV } \\
(20 \mathrm{MHz}-2 \mathrm{GHz})\end{array}$ & -76.3741 & \pm 7.3887 & -74.4022 & \pm 9.8143 & -73.7360 & \pm 9.4494 & -66.4082 & \pm 13.4290 \\
\hline $\begin{array}{l}\text { Solar burst moving Type IV } \\
(25-200 \mathrm{MHz})\end{array}$ & -80.9930 & \pm 3.8038 & -80.2606 & \pm 9.1897 & -79.7460 & \pm 8.0076 & -73.5093 & \pm 6.1723 \\
\hline $\begin{array}{l}\text { Solar burst flare continua } \\
(25-200 \mathrm{MHz})\end{array}$ & -82.7141 & \pm 4.6677 & -86.9271 & \pm 1.7974 & -85.9003 & \pm 1.4710 & -76.5644 & \pm 6.4405 \\
\hline $\begin{array}{l}\text { Solar burst Type V } \\
(10-200 \mathrm{MHz})\end{array}$ & -79.6217 & \pm 2.2213 & -86.9271 & \pm 1.7974 & -85.9003 & \pm 1.4710 & -76.5644 & \pm 6.4405 \\
\hline
\end{tabular}




\section{Frequency for Useful Radio Astronomical Observation}

Most of the radio astronomical sources that can be studied in this band are solar radio burst. However, due to the permanently and non-permanently RFI present at each site, radio astronomical sources such as a pulsar, deuterium line (DI) and solar radio burst observation are affected.

Fig. 7 until Fig. 10 show the spectrum survey done in the frequency range from $1-1000 \mathrm{MHz}$ for each site. It is found that there were three frequency ranges that have low RFI at each site selected which are useful for radio astronomical sources observation. For ECE, several frequency ranges are still free from interference (i) between $157.5 \mathrm{MHz}$ and 292.5 $\mathrm{MHz}$ with an average frequency of $-79.9774 \mathrm{dBm}( \pm 2.0600)$ (ii) between $337.5 \mathrm{MHz}$ and $472.5 \mathrm{MHz}$ with an average frequency of $-79.4585 \mathrm{dBm}( \pm 1.0868)$ and (iii) between $742.0 \mathrm{MHz}$ and $877.5 \mathrm{MHz}$ with an average frequency of $79.0419 \mathrm{dBm}( \pm 2.1533)$. At BCK, we have identified (i) between $1.0 \mathrm{MHz}$ and $299.0 \mathrm{MHz}$ with average frequency of $-84.8353 \mathrm{dBm}( \pm 3.6869)$ (ii) between $411.0 \mathrm{MHz}$ and 518.0 $\mathrm{MHz}$ with average frequency of $-74.7245 \mathrm{dBm}( \pm 3.7169)$ and (iii) between $720.0 \mathrm{MHz}$ and $913.0 \mathrm{MHz}$ with average frequency of $-75.1941 \mathrm{dBm}( \pm 2.0161)$ are the frequency ranges that are useful for radio astronomical sources observations. Based on Fig. 9, frequency ranges (i) between 1.0 $\mathrm{MHz}$ and $299.0 \mathrm{MHz}$ with average frequency of $84.1381 \mathrm{dBm}( \pm 3.2363)$ (ii) between $613.5 \mathrm{MHz}$ and 691.5 $\mathrm{MHz}$ with average frequency of $-77.0562 \mathrm{dBm}( \pm 0.4560)$ (iii) between $810.8 \mathrm{MHz}$ and $869.2 \mathrm{MHz}$ with average frequency of $-74.2309 \mathrm{dBm}( \pm 3.0668)$ have low RFI level and can be used for astronomical observation. Meanwhile at HSRDG, it is clearly seen (i) between $87.0 \mathrm{MHz}$ and 206.5 $\mathrm{MHz}$ with average frequency of $-80.5188 \mathrm{dBm}( \pm 2.8738)$ (ii) between $481.5 \mathrm{MHz}$ and $559.8 \mathrm{MHz}$ with average frequency of $-79.2035 \mathrm{dBm}( \pm 4.4822)$ (iii) between $796.0 \mathrm{MHz}$ and $849.5 \mathrm{MHz}$ with average frequency of $-74.2509 \mathrm{dBm}$ ( \pm 0.0997$)$ there were moderate interference in these bands.
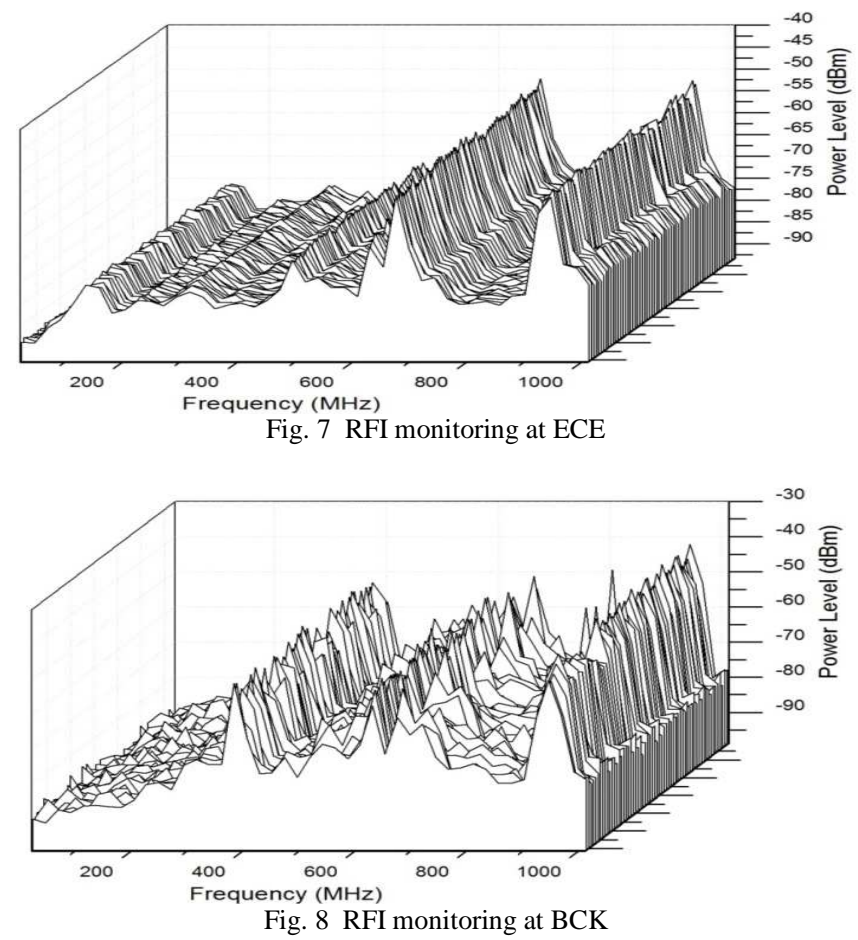

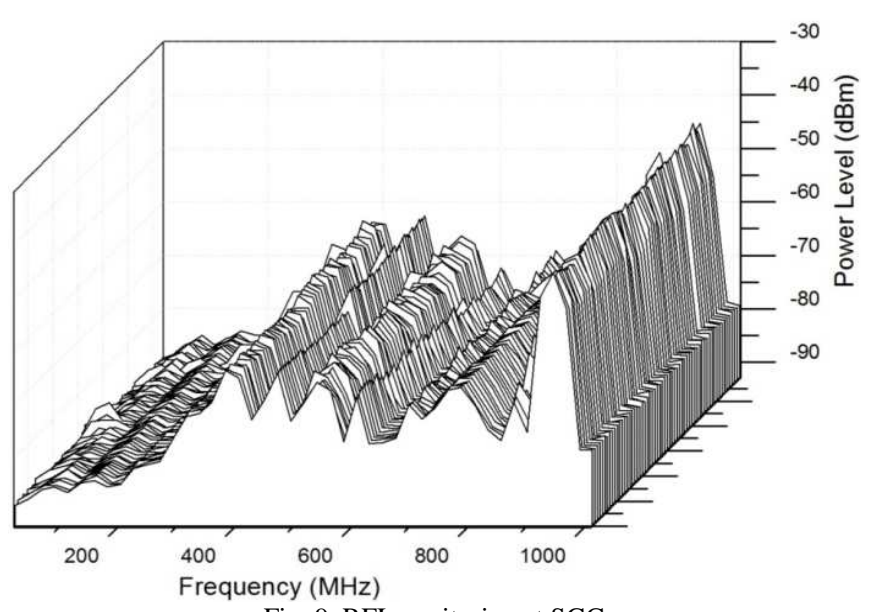

Fig. 9 RFI monitoring at SGC

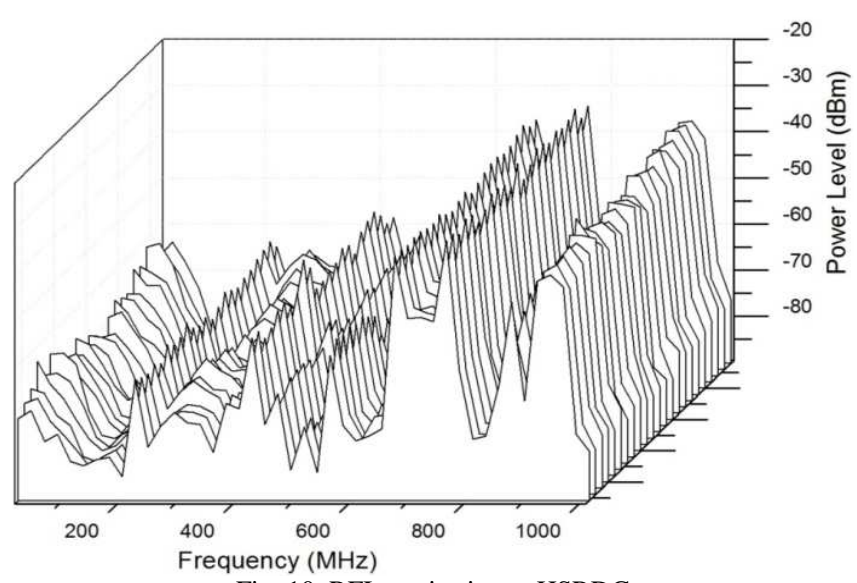

Fig. 10 RFI monitoring at HSRDG

\section{IV.CONCLUSION}

The purpose of this work was to analyze spectrum for frequency ranges between $1-1000 \mathrm{MHz}$ at different locations and to identify the best location for radio astronomical observation in Malaysia. RFI monitoring should be done first before setting up CALLISTO spectrometer for solar radio burst to produce a liable data. The results of spectrum survey and their interpretation are summarized here.

Prominent peaks were identified as $225.0 \mathrm{MHz}$ with power level $-76.7838 \mathrm{dBm}( \pm 8.6171), 382.5 \mathrm{MHz}$ with power level $-66.9760 \mathrm{dBm}( \pm 9.6458), 675.0 \mathrm{MHz}$ with power level $-58.1683 \mathrm{dBm}( \pm 16.6314), 877.5 \mathrm{MHz}$ with power level $-68.5803 \mathrm{dBm}( \pm 12.6756)$ and $945 \mathrm{MHz}$ with power level $-46.7981 \mathrm{dBm}( \pm 6.4968)$. These RFI sources are mostly coming from telecommunication system originate from the base station and residential area at certain sites. In these frequency ranges, radio astronomical sources that can be study are pulsar (50-600 MHz), deuterium line (327.384 $\mathrm{MHz}$ ) and solar radio burst Type I (80-200 MHz), Type II (20-150 MHz), Type III (10 kHz-1 GHz), stationary Type IV (20 MHz-2 GHz), flare continua (25-200 MHz) and Type V (10-200 MHz) [27]. The best sites to study these sources are at BCK compared to other sites due to its low RFI level.

Continuous RFI monitoring has to be done for RFI database in East Coast part of Peninsular Malaysia, and a map of Radio Quiet Zone (RQZ) in Malaysia using GIS technique similar to the previous study can be produced in 
the future. This study may help radio astronomers in Malaysia to refer to RFI database before conducting an observation [19].

\section{ACKNOWLEDGMENT}

This study is made possible by the usage of the grants RACE/F1/ST1/UNISZA/15-RR118, FRGS/1/2015/SG02 /UNISZA/02/1, UM-0000033/HRU.PT.CG(CR008-2015) and 68006/INSENTIF/60. The authors gratefully acknowledge Universiti Sultan Zainal Abidin, Universiti Malaya and Universiti Malaysia Terengganu for the financial and experimental support of this work. Special thanks are also dedicated to other researchers Electromagnetic Research Group (EMRG) and practical students from East Coast Environmental Research Institute (ESERI) for their assistance in this work.

\section{REFERENCES}

[1] Z. S. Hamidi, "Probability of solar flares turn out to form a coronal mass ejections events due to the characterization of solar radio burst Type II and III," International Letters of Chemistry, Physics and Astronomy, vol. 35, pp. 1-85, Jun. 2014.

[2] J. P. Wild, S. F. Smerd, and A. A. Weiss, "Solar bursts," Annual Review of Astronomy and Astrophysics, vol. 1, pp. 291-363, 1963.

[3] S. M. White, "Solar radio bursts and space weather," Asian Journal of Physics, vol. 16, pp. 189-207, 2007.

[4] Z. S. Hamidi and N. N. M. Shariff, "Investigation of radio frequency interference (RFI) profile and determination of potential astronomical radio sources," International Letters of Chemistry, Physics and Astronomy, vol. 5, pp. 43-49, Mar. 2014.

[5] J. Wilkinson, The Solar System in Close-Up, New York, USA: Springer, 2016.

[6] H. Koskinen and R. Vainio, Lectures on Solar Physics: From the Core to the Heliopause, Helsinki, Findland: University of Helsinki, 2009.

[7] ITU-R. (2004) RA.769: Protection criteria used for radio astronomical measurements. [Online]. Available: http://www.itu.int/rec/R-REC-RA.769-2-200305-I.

[8] Y. Huang, X. P. Wu, Q. Zheng, J. H. Gu, and H. Xu, "The radio environment of the 21 centimeter array: RFI detection and mitigation," Research in Astronomy and Astrophysics, vol. 16, pp. 110, Feb. 2016.

[9] A. A. Deshpande, "Correlations of spectral intensity fluctuations: Application to radio frequency interference mitigation," Radio Science, vol. 40, pp. 1-7, Oct. 2005.

[10] N. Gopalswamy. (2012) Solar radio bursts and space weather. [Online]. Available: https://ntrs.nasa.gov/archive/nasa/casi.ntrs.nasa.gov/20120015864.pd $\mathrm{f}$.

[11] R. P. Eatough, N. Molkenthin, M. Kramer, A. Noutsos, M. J. Keith, B. W. Stappers, and A. G. Lyne, "Selection of radio pulsar candidates using artificial neural networks," Monthly Notices of the Royal Astronomical Society, vol. 407, pp. 2443-2450, May 2010.

[12] M. Kesteven, D. Manchester, A. Brown, and G. Hampson, "RFI mitigation for pulsar observation," in Proc. RFI'10, 2010, p. 1.
[13] A. E. Rogers, P. Pratap, J. C. Carter, and M. A. Diaz, "Radio frequency interference shielding and mitigation techniques for a sensitive search for the $327 \mathrm{MHz}$ line of deuterium," Radio Science, vol. 40, pp. 1-10, Jun. 2005.

[14] Z. S. Hamidi, Z. Z. Abidin, Z. A. Ibrahim, N. N. M. Shariff, K. Basar, and S. Viridi, "Indication of radio frequency interference (RFI) sources for solar burst monitoring in Malaysia," AIP Conference Proceedings-American Institute of Physics, vol. 1454, pp. 43-46, Jun. 2012.

[15] Z. Z. Abidin, N. M. Anim, Z. S. Hamidi, C. Monstein, Z. A. Ibrahim, R. Umar, N. N. M. Shariff, N. Ramli, N. A. I. Aziz, and I. Sukma, "Radio frequency interference in solar monitoring using CALLISTO," New Astronomy Reviews, vol. 67, pp. 18-33, Aug. 2015.

[16] R. Umar, Z. Z. Abidin, and Z. A. Ibrahim, "The importance of site selection for radio astronomy," Journal of Physics: Conference Series, vol. 539, pp. 1-8, 2014

[17] Z. Z. Abidin, R. Umar, Z. A. Ibrahim, Z. Rosli, K. Asanok, and N. Gasiprong, "Investigation on the frequency allocation for radio astronomy at the L band," Publications of the Astronomical Society of Australia, vol. 30, pp. 1-10, Sep. 2013.

[18] R. Umar, Z. Z. Abidin, Z. A. Ibrahim, M. S. Hassan, Z. Rosli, Z. S. Hamidi, K. Basar, and S. Viridi, "Population density effect on radio frequencies interference (RFI) in radio astronomy," AIP Conference Proceedings-American Institute of Physics, vol. 1454, pp. 39-42, Jun. 2012.

[19] R. Umar, Z. Z. Abidin, Z. A. Ibrahim, Z. Rosli, and N. Noorazlan, "Selection of radio astronomical observation sites and its dependence on human generated RFI," Research in Astronomy and Astrophysics, vol. 14, pp. 241, Feb. 2014.

[20] Z. S. Hamidi, Z. Z. Abidin, Z. A. Ibrahim, N. N.M. Shariff, U. F. S U. Ibrahim, and R. Umar, "Preliminary analysis of investigation Radio Frequency Interference (RFI) profile analysis at Universiti Teknologi MARA," in Proc. IconSpace'11, 2011, p. 311.

[21] Z. S. Hamidi and N. N. M. Shariff, "Nonlinear behavior of the radio frequency interference (RFI) sources at Faculty of Applied Sciences, MARA University of Technology," International Letters of Chemistry, Physics and Astronomy, vol. 15, pp. 39-47, 2014.

[22] R. Umar, N. H. Sabri, Z. A. Ibrahim, Z. Z. Abidin, and A. Muhamad, "Measurement technique in radio frequency interference (RFI) study for radio astronomy purposes," Malaysian Journal of Analytical Sciences, vol. 19, pp. 960-965, Jul. 2015.

[23] Z. Z. Abidin, Z. A. Ibrahim, Z. Rosli, S. F. F. Malim, N. M. Anim, and Z. Noorazlan, "An RFI investigation for setting up a VLBI station below $2.8 \mathrm{GHz}$ in Malaysia," New Astronomy, vol. 17, pp. 6164, Feb. 2012

[24] R. Umar, S. N. Hazmin, Z. Z. Abidin, and Z. A. Ibrahim, "How to deal with radio astronomy interference," Publications of the Korean Astronomical Society, vol. 30, pp. 691-693, Sep. 2015.

[25] R. Umar, Z. Z. Abidin, and Z. A. Ibrahim, "Implementing the GIS technique for RFI mapping for radio astronomy in Malaysia," in Proc. IconSpace'11, 2011, p. 25.

[26] R. Mat, M. M. Shafie, S. Ahmad, R. Umar, Y. B. Seok, and N. H. Sabri, "Temperature effect on the tropospheric radio signal strength for UHF band at Terengganu, Malaysia," International Journal on Advanced Science, Engineering and Information Technology, vol. 6, pp. 770-774, Oct. 2016.

[27] N. Z. M. Afandi, Z. Z. Abidin, R. Umar, N. H. Sabri, Z. A. Ibrahim, and C. Monstein, "Implementation of frequency drift for identification of solar radio burst type II," International Journal on Advanced Science, Engineering and Information Technology, vol. 6, pp. 775-780, Oct. 2016. 